\title{
DETERMINATION OF CHARACTERISTIC PEROIDS OF SUPPRESSION OF THERMAL DECOMPOSITION REACTION OF FOREST FUEL MATERIAL BY SPECIALIZED SOFTWARE
}

\author{
Vladislav M. Gumerov ${ }^{1}$, Alena O. Zhdanova ${ }^{1, a}$, Maria M. Osmolovskaya ${ }^{1}$, Pavel A. Strizhak ${ }^{1}$ \\ ${ }^{1}$ National Research Tomsk Polytechnic University, 634050 Tomsk, Russia
}

\begin{abstract}
Experimental studies determining periods of suppression of thermal decomposition reaction of forest combustible materials was carried out by high-speed, cross-correlation cameras and panoramic techniques PIV and IPI under influence of water steam. Conditions and characteristics of reaction termination of thermal decomposition of forest combustible materials under reaction with steam cloud were defined.
\end{abstract}

\section{Introduction}

Forest fires causes a significant damage to ecology and economy of many countries [1,2]. Forest fires are harmful to the environment - from emissions of combustion products into the atmosphere to the complete destruction of vegetation cover over a large area. The task of forest protection is very relevant in the world at the present time [3].

Methods of aircraft extinguishing are traditionally used for extinguishing large forest fires $[4,5]$. However, the local measures are not always justified, since the water is poured on a small area of forest land. «Water spray», «steam curtain» received great fame. The complete elimination of combustion sourse is possible only under termination of thermal decomposition reaction in surface layers of forest combustible materials (FCM). Determining times of exposure of steam cloud on thermally degradable forest material, which are necessary for complete suppression of thermal decomposition reaction is interesting.

The aim of this research is determining of characteristic times of suppression of thermal decomposition reaction of forest fuel material under interaction with water steam.

\section{Experimental setup and procedure}

For experimental studies, we designed a setup; its scheme is depicted in Fig. 1. The main elements of the facility recording equipment are: a cross-correlation video camera 2 (image format is $2048 \times 2048$ pixels, frame rate is $1.5 \mathrm{~Hz}$, minimum delay between two successive frames is $5 \mu \mathrm{s}$ ), a high-speed video camera 1 (image format is $1024 \times 1024$ pixels, frame rate is up to 100000 frames per second), a double-pulse solid-state laser 14 (YAG active area with neodymium additives, wavelength is $532 \mathrm{~nm}$, minimum pulse energy is $70 \mathrm{~mJ}$, maximum pulse duration is $12 \mathrm{~ns}$, repetition rate is $15 \mathrm{~Hz}$ ), a

a Corresponding author: zhdanovaao@tpu.ru

This is an Open Access article distributed under the terms of the Creative Commons Attribution License 4.0, which permits unrestricted use, distribution, and reproduction in any medium, provided the original work is properly cited. 
synchronizing processor (maximum sampling signals is $10 \mathrm{~ns}$, support modes of external and internal start-up).

Each series of experiment includes several steps:

$\checkmark \quad$ a sprayer 8 tuning according to necessary parameters of gas-vapor-droplet mixture is joined to the output of a channel 5 connected to a container 3 ;

$\checkmark \quad$ the sprayer 8 is mounted on a tripod 6 by $0.5 \mathrm{~m}$ higher than the upper face of the cylinder 10 ;

$\checkmark$ the tripod height of a cross-correlation camera 2, and the installation height of a laser 14 are chosen so that the optical axis of the camera and a laser line 18 intersect at an angle of 90 degrees (the intersection point is located in the observed area of video frames);

$\checkmark \quad$ the cross-correlation camera 2 is calibrated (with the definition of a scale factor in a personal computer 4), and the "necking" of the laser line 18 is adjusted;

$\checkmark$ a FCM sample 12 is heated up by a local heating source to the temperature, which is significantly higher than the start temperature of its thermal decomposition $\left(T_{\mathrm{d}} \approx 500 \mathrm{~K}\right)$;

$\checkmark$ the temperature of combustion products and the FCM sample is monitored by two chromelalumel thermocouples 7 . The first thermocouple is placed at the upper part of the sample, the second one is installed at its lower part. The distance between thermocouples is chosen according to FCM thickness;

$\checkmark \quad$ when the FCM temperature achieves the values of $T_{\mathrm{d}}$, the process of spraying water into a flame combustion zone begins. Water droplet sizes vary in the range of $0.030<R_{\mathrm{d}}<0.100 \mathrm{~mm}$ in accordance with the recommendations given in papers [6]. Flow rate is $1.67 \mathrm{ml} / \mathrm{s}$ at a volume of 51 and a pressure of 2 bar;

$\checkmark \quad$ specialized software (which is the part of optical diagnostic techniques "Particle Image Velocimetry" (PIV) and "Interferometric Particle Imaging" (IPI)) runs in the personal computer 4 simultaneously with the process of spraying; thus, video images with the gas-vapor-droplet mixture are recorded;

$\checkmark \quad$ the temperature $\left(T_{\mathrm{m}}\right)$ of the gas-vapor-droplet mixture above the decaying FCM is controlled by a type $L$ thermocouple, in order to maintain its value in the range of 360-380 K [7];

$\checkmark$ the time interval is recorded, during which the temperature at the lower surface of the FCM sample becomes less than the accepted threshold temperature $\left(T_{\mathrm{d}} \approx 500 \mathrm{~K}\right)$.

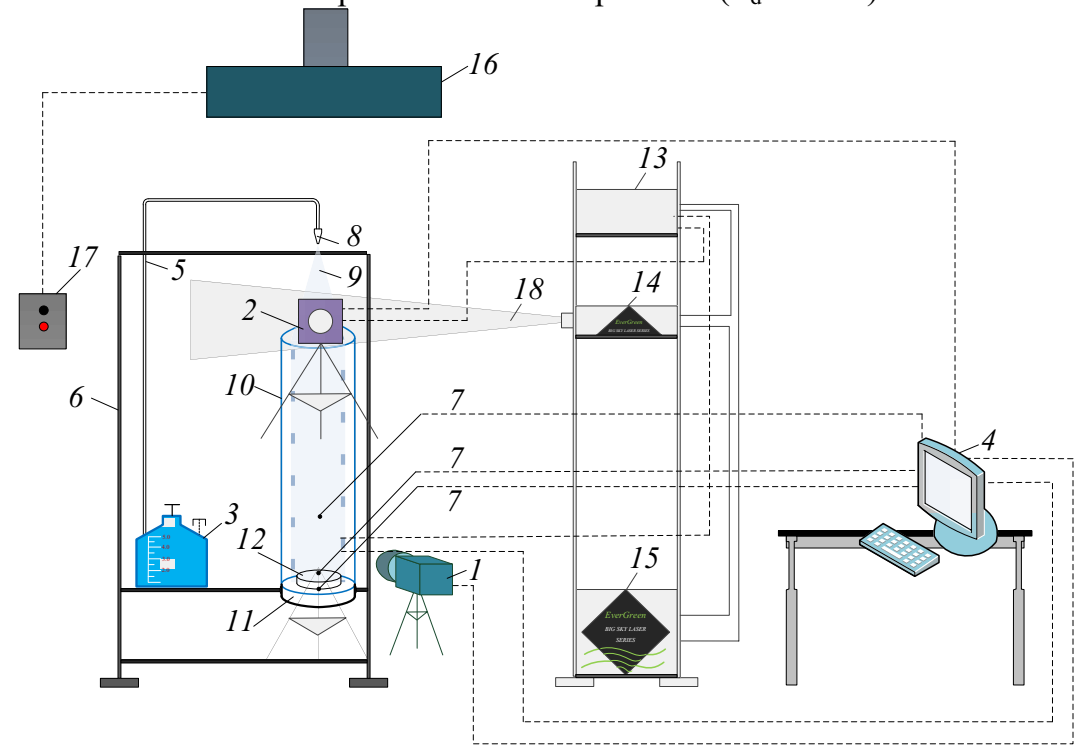

Figure 1. Experimental setup: 1 - high-speed video camera; 2 - cross-correlation camera; 3 - water container; 4 - personal computer; 5 - water supply channel; 6 - tripod; 7 - thermocouples; 8 - sprayer; 9 - water flow; 10 hollow cylindrical channel; 11 - substrate; 12 - FCM weighed portion; 13 - synchronizer for personal computer, cross-correlation camera, and laser; 14 - solid double-pulse laser; 15 - laser line generator; 16 - air flow system; 17 - remote control of air flow system; 18 - laser line 
The initial water temperature $T_{\mathrm{w}}$ and the temperature at the FCM sample surface $T_{\mathrm{d}}$ are measured by type $L$ thermocouples. We applied a technique of thermocouple measurements similar to that used in previous studies [8]. Systematic errors in measuring temperatures $T_{\mathrm{d}}$ and $T_{\mathrm{w}}$ do not exceed $2.5 \%$, droplet sizes $-1.5 \%$, tracer velocities $-2 \%$. Random errors in measuring the temperature are about $19 \%$.

\section{Results and discussion}

We take birch leaves and spruce needles as the FCM; as a quenching liquid is water with special inclusions (tracers), representing the admixture of titanium dioxide nanopowder $(0.5 \%$ by weight). The latter is introduced to enhance the contrast of video recordings obtained by the cross-correlation camera. We choose $\mathrm{TiO}_{2}$ particles as tracers, since they do not dissolve in water [9]. The initial temperature of spray water is assumed to be constant $\left(T_{\mathrm{w}}=\right.$ const $)$ and is about $300 \mathrm{~K}$. Fig. 2 shows a videogram of an experiment with a suppression of a thermal decomposition reaction by a water-vapor mixture in the case of burning birch leaves with the sample thickness of $0.04 \mathrm{~m}$.

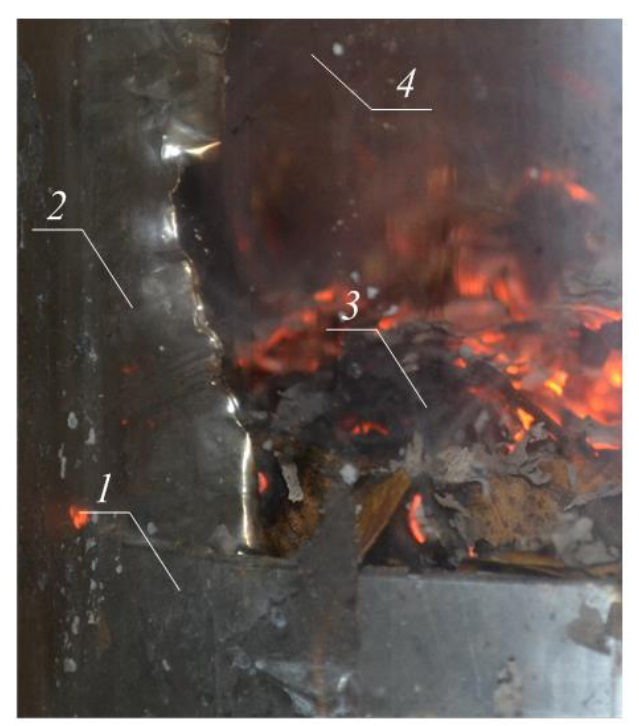

Figure 2. Videogram of an experiment with the suppression of the FCM thermal decomposition reaction (birch leaves) by a water-vapor mixture at $L_{\mathrm{f}}=0.04 \mathrm{~m}$ : 1 - metal substrate; 2 - hollow cylinder; 3 - forest combustible material; 4 - water-vapor mixture

The dependences of characteristic times $\left(t_{\mathrm{d}}\right)$ of suppressing the thermal decomposition reaction of FCM on the thickness of the reacted layer FCM $\left(L_{\mathrm{f}}\right)$ are shown in Fig. 3. 


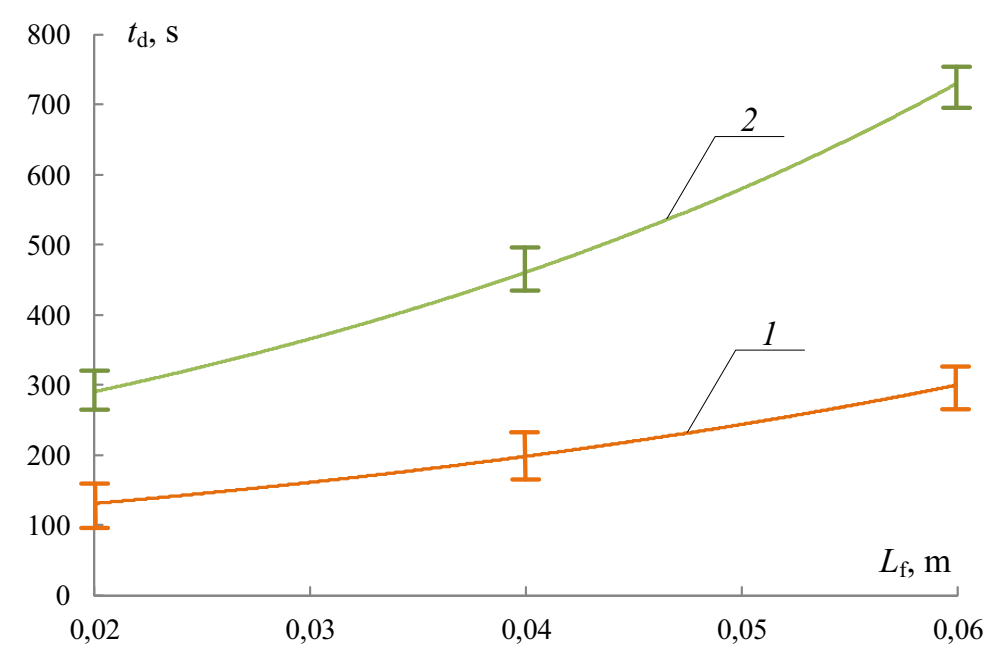

Figure 3. Characteristic times of suppressing the FCM thermal decomposition reaction: 1 - birch leaves, $2-$ spruce needles

\section{Conclusion}

Resulting the conducted experiments, we established, that thermal decomposition reaction of FCM is terminated within a period not exceeding $300 \mathrm{~s}$ for birch leaves and $730 \mathrm{~s}$ for spruce needles with thickness of the reacted layer not more than $0.06 \mathrm{~m}$. The recieved values may be considered limiting, because under conditions of real ground fire the thickness of forest cover, which burn out, is not more than $0.05 \mathrm{~m}$.

In accordance with experimental results we can conclude, that dumping large volumes of water slug for extinguishing forest fires is inexpedient.

The investigation was supported by Russian Science Foundation (project 14-39-00003).

\section{References}

1. J. Qie, L. Yang, Y. Wang, J. Dai, X. Zhou, J. of Fire Sci., 29, 3 (2011).

2. J.L. Rossi, A. Simeoni, B. Moretti, V. Leroy-Cancellieri, Fire Safety J., 46, 8 (2011).

3. J. Urbas, Fire and Materials, 37, 8 (2013).

4. O.P. Korobeinichev, A.G. Shmakov, V.M. Shvartsberg, A.A. Chernov, S.A. Yakimov, K.P. Koutsenogii, V.I. Makarov, Fire Safety J. 51 (2012).

5. X.K. Xiao, B.H. Cong, X.S. Wang, K.Q. Kuang, Richard K.K. Yuen, G.X. Liao, J. of Fire Sci. 29, 4 (2011).

6. R.S. Volkov, G.V. Kuznetsov, P.A. Strizhak, Int. J. of Heat and Mass Transfer 79 (2014).

7. P.A. Strizhak, J. of Eng. Phys. and Thermophys. 86, (4) (2013).

8. D.O. Glushkov, P.A. Strizhak, Advances in Mechanical Eng. 2014, Article ID 269321 (2014).

9. J.M. Foucaut, M. Stanislas Measurement Sci. and Technol. 13 (2002). 